\title{
Acute coronary syndromes and diagnostic methods
}

\author{
Mustafa Enes Demirel ${ }^{1 *}$, Ibrahim Donmez ${ }^{2}$, Erhan Renan Ucaroglu ${ }^{3}$ and Ahmet Yuksel ${ }^{3}$ \\ ${ }^{1}$ Department of Emergency Medicine, Duzce University Faculty of Medicine, Turkey \\ ${ }^{2}$ Department of Cardiology, Zonguldak Atatürk State Hospital, Turkey \\ ${ }^{3}$ Department of Cardiovascular Surgery, Abant Izzet Baysal University Faculty of Medicine, Turkey
}

\section{Acute coronary syndrome}

Acute coronary syndrome is defined as a clinical presentation often accompanied by acute chest pain or other myocardial damage markers and changes on ECG due to impaired blood flow of heart muscle.

ACS involves arterial thrombotic diseases such as unstable angina pectoris (USAP), non-ST elevation myocardial infarction (NSTEMI) and ST-elevation myocardial infarction (STEMI) [1]. Definition of acute coronary syndrome according to the guidelines by American and European heart societies is shown in table 1 [2].

\section{Epidemiology}

Despite decreased incidence and mortality rates in recent years, coronary heart diseases remain one of the leading causes of death. According to TEKHARF study by the Turkish Cardiology Society, 2 million people have coronary artery disease in Turkey. According to TEKHARF data, cardiovascular diseases are responsible for $45 \%$ of all deaths in our country [3]. It is estimated that the number of patients with heart disease will reach 3.4 million if this negative situation, similar to the rates in developed countries, continues [2].

Increasing incidence of NSTEMI and STEMI with age may be related to a triggering factor such as inflammation. NSTEMI is known to be often accompanied by comorbidities such as diabetes mellitus and renal failure.

\section{Physiopathology}

Myocardial ischemic symptoms are mostly resulted from disrupted integrity of vulnerable atherosclerotic plaque [4]. Acute coronary syndrome is caused by occlusive thrombus in more than $90 \%$ of cases [5].

Atherosclerosis is a chronic condition progressing up to the occlusion of the vessel, which begins in the intima of the artery [6]. This process influences entire vasculature. Intima and media layers develop plaque. Rupture or erosion of the plaque is required in order to become a thrombus [7]. Acute ischemic events begin as a result of plaque rupture, endothelial damage, inflammation and release of some mediators. Impaired integrity in the arterial wall stop the flow

Table 1. ESC/ACC* definition of acute coronary syndrome

1. Rapid elevation of CK-MB and relatively slow elevation of troponins that are among myocardial damage markers accompanied by at least one of the following factors

- Ischemic symptoms

- Pathologic Q waves on ECG

- ECG findings compatible with myocardial damage

- Intervention to coronary artery

2. Pathological findings of acute coronary syndrome

* ESC/ACC: European Society of Cardiology / American College of Cardiology in the vessel lumen, causing ischemia and damage [8]. Diffuseness of necrosis varies depending on the presence of collateral flow, duration of ischemia and the extent of the involved area.

The thrombus obstructing the vessel lumen is a mixture of clots consisting of platelet rich fibrin and erythrocytes. Although there are several factors regarding time of the occurrence of acute coronary syndrome, decreased fibrin degradation activity due to increased levels of platelet aggregation and plasminogen activator inhibitor plays a role in occurrence of plaque fissure and rupture often early in the morning [9].

USAP, NSTEMI or STEMI occurs based on prevention of blood flow in the vessel lumen by growth of the plaque or degree of the obstruction in the vessel lumen as a result of thrombus occurring due to plaque rupture [10]. Pathological studies in patients with NSTEMI acute coronary syndrome have found myocardial damage areas in the sites supplied by the relevant vascular structure [11].

\section{Risk factors}

There are numerous risk factors in the etiology of coronary artery diseases. Roughly, these risk factors can be divided into two groups as changeable and unchangeable factors. These risk factors are shown in table 2 .

Age: Being aged over 45 years in men and 55 years in women is accepted as a risk factor for developing atherosclerosis.

Sex: Although mortality occurs in older ages among women, the rate of mortality is higher. This might be attributed to that women are more overweight in middle-advanced ages, more often have diabetes and hypertension, more commonly use oral contraceptives, and have higher cholesterol levels compared to men $[12,13]$.

Family History: In many studies, patients with a family history of early coronary artery disease have been shown to carry a 1.5 to 1.7 folds higher risk, indicating the importance of family history. Cholesterol levels are increased in families with a history of premature MI and associated mortality. This is an independent risk factor alone [14,15].

Smoking: Smoking is an important and changeable risk factor of atherosclerosis. In addition, the mortality rate can be raised even

*Correspondence to: Mustafa Enes Demirel, Department of Emergency Medicine, Faculty of Medicine, Düzce University, Düzce, Turkey, Tel: +90 505 391 0903, E-mail : mnsdmrl@hotmail.com

Received: November 14, 2019; Accepted: December 02, 2019; Published: December 05, 2019 
Table 2. Risk Factors

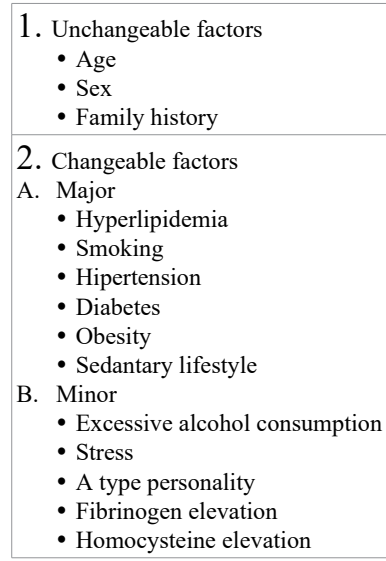

2. Changeable factors

A. Major

- Hyperlipidemia

- Smoking

- Hipertension

- Diabetes

- Obesity

- Sedantary lifestyle

B. Minor

- Excessive alcohol consumption

- Stress

- A type personality

- Fibrinogen elevation

- Homocysteine elevation

with exposure to cigarette smoke [16]. Mortality rates of those who quit smoking decrease by $36 \%$ compared to those who did not quit, regardless of age and gender [17].

Smoking triggers other mechanisms in addition to its negative effects on sympathetic activity of the body and decreased oxygen consumption of the heart muscle. Chronic smoking accelerates atherosclerotic process and increases LDL oxidation. Nitric oxide biosynthesis and endothelium-dependent vasodilatation are impaired following smoking $[18,19]$.

Hypertension: Hypertension has an increasing prevalence. A diastolic or systolic elevation in blood pressure has been associated with cardiovascular mortality and morbidity [20]. A decrease of 5-5 mmHg in blood pressure decreases the risk of developing both cerebrovascular disease and coronary artery disease [21]. Therefore, hypertension is considered a factor increasing risk of cardiovascular disease.

Diabetes Mellitus: In diabetic patients, functions of endothelial and smooth muscles are impaired, and atherosclerotic load is increased because of the increased platelet adhesion, which is a critical step of atherogenesis, compared to non-diabetic persons [22]. When diabetic patients have been compared with race and age matched persons without diabetes mellitus, future risk of diabetic patients has been found as 2 to 4 times higher [23]. In a study by $\mathrm{Gu} \mathrm{K}$ et al., $75 \%$ of deaths were found to be resulted from coronary artery disease in diabetic patients [24].

Hyperlipidemia: The risk of coronary artery disease shows correlation with blood cholesterol levels [25]. Comprehensive clinical trials have shown a decrease in cardiovascular diseases by dropping LDL cholesterol levels with various means and treatment. Therefore, the correlation of atherosclerosis with cholesterol is widely recognized [26].

Understanding of vascular physiology in atherosclerosis has been convincing about the responsibility of LDL cholesterol for the development of atherosclerosis. Mutations of LDL receptor in patients with familial homozygous hypercholesterolemia, cause hypercholesterolemia resulting in atherosclerosis at early periods of life.

Obesity: Obesity is epidemiologically associated with an increased vascular risk [27]. However, the pathophysiology of risk effect on vascular structure is still controversial.

Stress: Among changeable risk factors, stress increases vascular risk. It can worsen myocardial ischemia by increasing oxygen consumption through adrenergic stimulation. Stress can cause vasoconstriction, decreasing oxygen supply [28].

Because clinic depression increase the prevalence of smoking, sedentary life and hypertension, its effect continues even if the other risk factors are resolved [29].

Sedentary Life: Exercise, which moderately affect LDL and total cholesterol levels, provide a steady increase in HDL and a decrease in triglyceride levels. In addition, as regular exercise cause a decrease in blood pressure, it reduces the risk to a level comparable with many drugs [30].

Regular exercise decreases risk factors that can cause atherosclerosis. It reduces the level of $\mathrm{C}$ reactive protein and regulates its endothelial function. Exercise regulates the variables that control plasma viscosity such as plasminogens and fibrins, showing a positive effect in regulation of hemostatic parameters [31].

Alcohol: It is known that high levels of alcohol consumption disrupt myocardial contractility and even may cause cardiomyopathy. Although HDL levels are higher in alcohol abusers; studies have shown that the risk is increased due to raised blood pressure in people with moderate-to-high alcohol consumption [32].

\section{Types of acute coronary syndromes}

Acute coronary syndromes are divided into two groups according ST segment change on ECG as non-ST elevation and ST-elevation [33]. These groups are shown in figure 1.

NSTEMI Acute Coronary Syndrome: In NSTEMI thrombus, which did not lead to complete occlusion in the ruptured or eroded plaque is responsible for the pathophysiology. This is a white thrombus with low number of fibrins [34]. There is acute coronary syndrome presentation and ST elevation is not observed. Syndromes with this clinical picture are divided into two groups as USAP and NSTEMI. These groups are evaluated together as pathophysiology, clinic and treatment approach are similar between these groups.

USAP is a clinical table in form of severe exercise angina or changed characteristics, which lasts longer than 20 minutes in resting. It defines the clinic between stable angina pectoris and MI. It is distinguished from NSTEMI with serum markers [35]. Cardiac enzymes are elevated in NSTEMI. Although Q wave is not observed in most patients, some

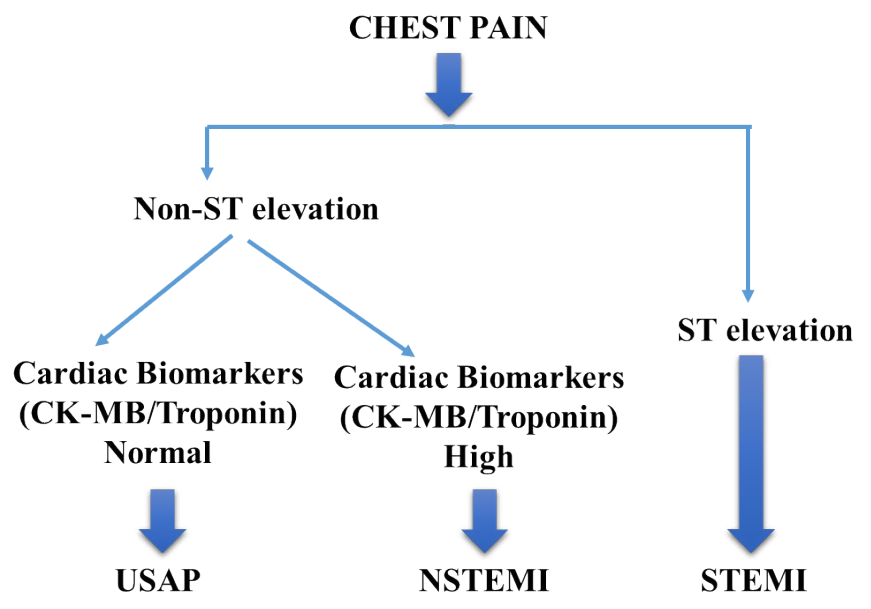

Figure 1. Types of acute coronary syndromes 
studies have observed Q wave between 2-15\% [36, 37]. Among cardiac markers, troponin is a more precise indicator of myocardial necrosis. The condition in which cardiac troponin is elevated, but CK-MV levels are not, is evaluated as low myocardial damage. This is clinically significant, because it is of clinical importance in outcome and treatment [38].

STEMI Acute Coronary Syndrome: In the events where constant and occlusive thrombus is predominant, ST is elevated and this often indicate total obstruction of acute coronary artery. Approximately 30 minutes after complete occlusive lesion, necrosis begins at the subendocardium and begins to expand in the subepicardium [39]. Occlusion is resulted from thrombus clustering in thrombosis. Afterwards, fibrin plays a role in the consolidation of the plug in the early period [40].

\section{Diagnosis of Acute Coronary Syndrome}

Early diagnosis is important in acute coronary syndrome. It is easy to establish the diagnosis in the presence of findings on ECG. However, a considerable number of cases have no ST elevation [41]. A good anamnesis is often diagnostic. Some cases require cardiac enzymes and ECG follow-up.

The most challenging cases for clinicians include presentations with atypical signs without significant ST elevation, and the cases showing bundle branch block and ventricular hypertrophy.

Anamnesis: Typical symptoms of acute coronary symptom sensation of retrosternal pressure or burn radiating to the left arm or neck. In addition to this sign, there may be other complaints such as vomiting, dyspnea, syncope and sweating.

On the contrary, there may be acute coronary syndrome presentations with atypical symptoms. These complaints may show symptoms similar to pleuritic and musculoskeletal pains that could lead us to other diagnoses. Atypical symptoms are more common in young, female gender, patients with renal failure, diabetes and dementia.

Physical Examination: Physical examination is usually normal in acute coronary syndrome. Some patients may have a fear of death, sympathetic discharge related restlessness, anxiety, tachycardia and hypertension, while some MI patients may have bradycardia and hypotension.

Other possible examination findings include splitting of S2, murmur of mitral regurgitation and changes in the characteristics of apical beat. In some cases pulmonary rales may be heard.

Electrocardiogram: ECG is the leading tool that can be used in the diagnosis. The first thing to do is ordering a 12-lead ECG in suspected cases. Making a comparison with previous ECG of the patient can increase its diagnostic value. It is important to repeat it during observation in terms of comparison. Sensitivity of ECG is not higher than $10 \%$ and specificity $\tan 90 \%$.

Changes of ST in the repeated ECG may be seen especially in Prinzmetal's angina [38].

A ST segment elevation $\geq 1 \mathrm{~mm}$ in two or more adjacent derivations, and $\mathrm{T}$ negativity in derivations with dominant $\mathrm{R}$ wave strongly suggest acute coronary syndrome (38). A ST elevation $\geq 0.5 \mathrm{~mm}$ is considered significant by American guidelines [42].

Completely normal ECG does not rule out the possibility of acute coronary syndrome [43]. Studies have reported MI or USAP in approximately $10 \%$ of the patients who were discharged because of normal ECG [41].
Biochemical Markers: Some molecules are released from myocytes with impaired integrity due to onset of myocardial damage first into the interstitium and than into the circulation with vascular structures and lymphatics. Molecules such as CK, CK-MB, myoglobin, AST and $\mathrm{LDH}$ are found in the myocardial tissue.

According to a consensus report by European Society of Cardiology (ESC) and American College of Cardiology (ACC), the diagnosis of myocardial infarction can be made in the case of elevated CK-MB and troponin accompanied with symptoms compatible with myocardial ischemia [36].

- Creatine Kinase: Creatine kinase, which has three isoenzymes, is the most valuable marker following troponin. It elevates above normal level within 4-8 hours after acute damage, and peaks at the 24th hour. Although it varies from person to person, it regresses to normal levels in 3-4 days [44]. It can be used in detection of reinfarction at an early period and in hospital since it rapidly raised and is detected in blood.

Whereas MM isoform is concentrated in the skeletal muscle, isoenzyme $\mathrm{BB}$ is concentrated in the brain and kidneys. MB isoenzyme is the cardiac-sensitive isoform.

Creatine kinase may show false positivity in many disorders such as skeletal muscle trauma, intramuscular injections, heart failure, exercises and epileptic seizures.

- Myoglobin: Low molecular weight myoglobin is a sensitive, but nonspecific protein. It raises about within 2 hours at the early period. Non-elevation of myoglobin rules out the diagnosis of myocardial infarction. Although its specificity is low, rapid elevation makes it of importance $[45,46]$.

- Troponin: Troponin (Tn), which plays a role in contractility in the skeletal and heart muscles, is a molecule regulating the relationship between actin and myosin. Tn has three subtypes. $\mathrm{Ca}++$ binding Tn C, Tn I which blocks actin-myosin interaction and Tn T which anchors the complex with thin filament structures.

Cardiac troponins can show necrosis, but do not provide information about the cause.

Tn T raises within 12 hours after the damage, and peaks at the 24th hour. It may remain high in the blood up to 14 days. Tn I begins to elevate approximately at the 6th to 12 th hours, peaks at the 24 th hour and may be found high in the blood for about 10 days [47,48].

Troponins are more sensitive than CK-MB. Levels of troponins can be guiding for clinicians in risk determination schemes. It is not appropriate to rule out the diagnosis based on troponin values. A follow-up over 6-12 hours is necessary to rule out acute coronary syndrome.

According to the risk classification by the American Heart Association (AHA), Tn T values between $0.01-0.1 \mathrm{ng} / \mathrm{mL}$ show moderate risk in NSTEMI patients. In the case of a Tn T value $>0.1 \mathrm{ng} /$ $\mathrm{mL}$, the patient is at a high prognostic risk [42].

Similar to creatine kinase, Tn may be high in conditions other than acute coronary syndrome. Troponin may be high in many situations including myocarditis, cardiac trauma, resuscitation, pulmonary embolisms and tachyarrhythmias [9].

- B type Natriuretic Peptide (BNP): BNP is a neurohormone released following tension of the ventricles. It has several features such as natriuresis, diuresis and vasodilator. It is of importance in determination of disorders, because BNP is synthesized and released in a short time. It has a short half-life $[49,50]$. 
BNP can be helpful in distinguising cardiac and non-cardiac causes of dyspnea as well as it can be used as a screening method high-risk groups for left ventricular systolic dysfunction and in some vascular disease.

It is particularly used in treatment evaluation and follow-up in heart failure. It is of paramount value in the differential diagnosis in emergency departments [51]. Whereas troponins are rather ischemia markers, BNP is associated more with heart failure and death [52].

\section{Risk classification}

TIMI risk score was developed by the Thrombolysis in Myocardial Infarction work group (TIMI) in order to determine the possibility and treatment strategy and to predict the prognosis when diagnosing acute coronary syndrome. This is a risk classification based on low, moderate and high risk classes according to total score obtained by giving 0 or 1 point for each parameter. Patients with a 5 and higher points are classified as high-risk group, 3-4 points in moderate risk group and 0-2 points in low risk group [53]. TIMI data were obtained in ESSENCE and TIMI-11B, and the validity was confirmed in patients groups of studies including those conducted by Mayo Clinic $[54,55]$. New and repeating myocardial infarction, emergency revascularization and all cause mortality have been reported by $26-40 \%$ in high-risk group, $13-$ $20 \%$ in moderate-risk group and $4-8 \%$ in low risk group over 14 days [56]. TIMI risk score for NSTEMI patients is shown in Table 3. Each parameter is scored with 1 point.

FRISC, RITA 3 and TACTICS studies conducted in patients diagnosed with NSEMI have reported that early application of invasive treatment decreased primary outcomes. However, early invasive intervention was not beneficial in all cases. Nevertheless, costs and likelihood of complications were in negative direction. A scoring system was developed in order to select eligible patients instead of all patients. Parameters of the FRISC risk score, which was developed with 1-year patient data, include age, gender, diabetes mellitus, ST depression, previous history of MI, elevated troponin, increased IL-6 or CRP. Early invasive method is recommended in patients who received points from 3 or more criteria [57-59]. FRISC risk score is shown in table 4. Each parameter is scored with 1 point.

In GUSTO study, the factors associated with mortality include age, low systolic blood pressure, tachycardia, high Killip class and anterior infarction. Killip classification is given in table 5 [60]. In GUSTO-1

Table 3. Risk score parameters for NSTEMI and USAP

1. $>65$ Years old

2. Having more than 3 risk factors for coronary artery diseases

3. $>50 \%$ previously known stenosis

4. 2 or more angina within 24 hours

5. Elevated troponin level at follow-up

6. Presence of symptoms within the last 7 days despite using aspirin

Table 4. FRISC risk score

1. $>70$ years old

2. Gender

3. Diabetes

4. Elevated troponin

5. ST depression on ECG

6. History of previous MI

7. Increased interleukin- 6 or CRP

\section{Table 5. Killip Classification}

1. Stage 1: No rales and $\mathrm{S} 3$. No signs indicating heart failure

2. Stage 2: Rales + and $\mathrm{S} 3$.

3. Stage 3: $\mathrm{S} 3+$ More than $50 \%$ rals

4. Stage 4: Cardiogenic shock. study, mortality rate was $1.1 \%$ in patients aged under 45 years, while this rate was $20.5 \%$ in patients aged over 75 years, supporting that age is a strong predictor in these patients [61].

GRACE risk score that can be used in all patients with acute coronary syndrome predicts mortality up to 6 months. When used with other risk scoring systems, GRACE, which includes data of a wide patient group, gives better results. The parameters used in GRACE scoring include age, systolic blood pressure, heart rate, presence of ST depression, Killip class, cardiac markers and cardiac arrest [62].

One of the risk parameters that should be considered in acute coronary syndromes is evaluation of ventricular functions. There is an inverse correlation between left ventricular ejection fraction and mortality. Left ventricular functions should be evaluated in patients diagnosed with MI [63].

\section{Cardiac physiology end evaluation}

\section{Cardiac electrophysiology}

Heart conduction system regulates cardiac cycle with specialized fibers. Eac beat consists of 3 consecutive phases. These phases of the cycle are:

\section{Contraction (systole)}

2. Relaxation (diastole)

\section{Filling phase (diastole)}

Contraction phase of the heart is known as systole. After the electrical signal create contraction with filling of the blood into the right atrium, it passes from the atrium to the ventricle through AV node in a delayed way to create ventricular contraction. The blood in the ventricle is pumped into the pulmonary trunk and aorta during the systolic phase. Relaxation follows the systolic phase. In this period, the blood is filled again with negative pressure. The aorta and pulmonary valve are closed at the beginning of the diastolic phase. Whereas atrioventricular valves are closed and pulmonary valves are opened during the systolic phase.

Systolic Phase: $55-70 \%$ of the blood is pumped to the periphery and lungs during the systolic phase. This phase consists of two stages.

1. Preejection stage is the time of isometric contraction, begins with the first heart sound or closing of AV valves, and involves the time to the opening of the semilunar valves. Volume does not change, but pressure is increased during this time.

2. Ejection stage begins with the opening of the aorta and pulmonary valves. Volume is rapidly decreased at the early period with sudden pressure increase and pumping of the blood into the aorta. This stage ends with the closing of the valves [64].

Diastolic Phase: The time from the closing of the aortic valves to the opening of the mitral valve is clinically defined as diastolic phase. Normal diastolic function is defined as the maintenance of enddiastolic volume at rest or during exercise without raising the diastolic pressure above $12 \mathrm{mmHg}$ [65].

In relaxation phase, it is the phase to return pre-contraction, and this phase is energy dependent. The myofibrils return to their precontraction length with working of $\mathrm{Na}-\mathrm{K}$ and calcium pumps.

Systolic relaxation begins in the middle of the systolic phase and lasts up to $1 / 3$ of diastolic period. Isovolumetric relaxation time is measured with PW doppler. It is time until the colsing of the aortic valve 
and opening of the mitral valve, while left ventricular volume remains constant [64]. It is influenced by the factors affecting the closing time of the aortic and mştral valves [66]. Isovolumetric relaxation time continues with rapid filling time.

Rapid filling phase begins with the opening of the mitral phase. A passive blood flow occurs with the opening due to the difference of a few $\mathrm{mmHg}$, and continue until intraventricular pressure becomes equal to the left atrium pressure. Atrioventricular flow rate depends on flexibility and ventricular relaxation with pressure difference. Although the flow is passive, ventricular relaxation is a period requiring energy. Filling of the left ventricle with blood is a passive event, showing contractility of the myocardium. The more myocardium relaxes, the better the volume can it pump.

Pressure decrease in unit time is found with '-dP/dt'. It should be recorded with left ventricular pressure monitoring. It peaks with the closing of the aortic valve. As the rate will be decreased in the case of prolonged relaxation, the negative value will be decreased. Negative value is increased in sympathetic signals as the relaxation will be accelerated. Maximal value will not provide information on all events in the relaxation phase since it is an instant value. The most negative aspect of the left ventricle is to be influenced by the aortic pressure [67]. Because it increases independently from relaxation values when left ventricular pressure and aortic pressure increase [68].

There are several definitions for diastolic dysfunction: (1) an average pulmonary capillary pressure $<12 \mathrm{mmHg}$, [2] right-shift of pressure-volume relationship with presence of ventricular filling resistance, (3) inability to provide ventricular filling capacity without a compensatory increase in the left atrium pressure [66].

Recent studies have shown that the main impairment occurs in diastolic functions at an early stage. According to Starling's law, lowpressure ventricle that could not be filled with a sufficient pressure increases atrium pressure over time in order to compensate [69]. Diastolic function is affected by compliance, relaxation, myocardial stress, heart rate and pericardial restriction [70].

Tau coefficient, which is known as the relaxation coefficient was formulized for the first time by Weiss et al. Being affected by afterload independently from preload shows the importance of Tau coefficient [71].

In addition to echocardiography, magnetic resonance imaging (MRI), ventriculography and invasive procedures are also used in the diagnosis of diastolic dysfunction [72]. Today the most commonly used method is Doppler echocardiography [73].

Measurement of cardiac flow rates when evaluating diastolic functions with Doppler, gives many clues in terms of dysfunction and prognosis.

In a normal physiological rhythm, flow from the left atrium to the left ventricle, which is measured via the mitral valve consists of two components.

\section{E wave reflects early phase of diastolic filling}

\section{A wave reflects atrial contraction in the late diastolic phase}

Because flow rate through the valve depends on transmitral pressure difference, $\mathrm{E}$ wave rate is influenced by both diastolic relaxation rate and left atrium pressure. Change pattern of $\mathrm{E}$ wave rate will give clues about left ventricular diastolic dysfunction and prognosis. These flow parameters are highly sensitive in showing diastolic functions.
Another diastolic evaluation is to assess the flow from the pulmonary veins to the left atrium with Doppler. Studies have shown that mitral flow is influenced by age.

Diastolic functions have been classified into four groups as normal, impaired relaxation, pseudonormal and restrictive patterns according to the standard diagnostic criteria and flow curves are shown in figure 2.

1. Normal pattern: E/A ratio is lower than 1 in young and healthy persons. Deceleration time is under $220 \mathrm{~ms}$. IVRT is lower than $100 \mathrm{~ms}$.

2. Impaired (prolonged) relaxation pattern: E/A ratio is lower than 1 . This pattern begins to be seen with advanced age. Deceleration time and relaxation time increase. E flow rate decreases. A flow rate increases. Deceleration time is under $220 \mathrm{~ms}$.

3. Pseudonormal pattern: This is the stage where filling pressure exceeds the upper limit as a result of decreased flexibility and prolonged relaxation. Left atrium pressure is further high. Compliance decreases in addition to the prolonged relaxation. The difference between atrium backflow and transmitral A flow is expected to be higher than $35 \mathrm{~cm} /$ sec in pulmonary flow analysis conducted for distinguish this pattern from the normal pattern. In normal pattern, AR is lower than $35 \mathrm{~cm} /$ sec. Whereas in pseudonormal pattern, E/A ratio is expected to be $>1$ and deceleration time between $150-200 \mathrm{~ms}$. IVRT is $<100 \mathrm{~ms}$ in this pattern.

4. Restrictive pattern: Myocardial wall stability is at the forefront. Flexibility and relaxation disappear [74-76]. There is a high left atrium pressure. Ventricular filling pressure increases [77]. E flow rate is $1 \mathrm{~m} /$ $\mathrm{sec}$, deceleration time is shortened with progression of the disease and is lower than $150 \mathrm{~ms}$. E/A ratio is higher than 1.5.

\section{Evaluation of Cardiac Functions}

2003 guidelines of the American College of Cardiology stated "The use of echocardiography in acute coronary syndrome" as a procedure in Class I category [6].

The presence of wall motion anomaly in an important indicator of ischemia or infarction area. Regional left ventricular wall motions and general ventricular function can be analyzed and evaluated using many methods. These are classified as semi-quantitative and quantitative evaluations [6].

The first impaired echocardiographic parameter in acute ischemia is diastolic function, while systolic dysfunction occurs later. It manifests as segmental wall motion disorder on echocardiography.

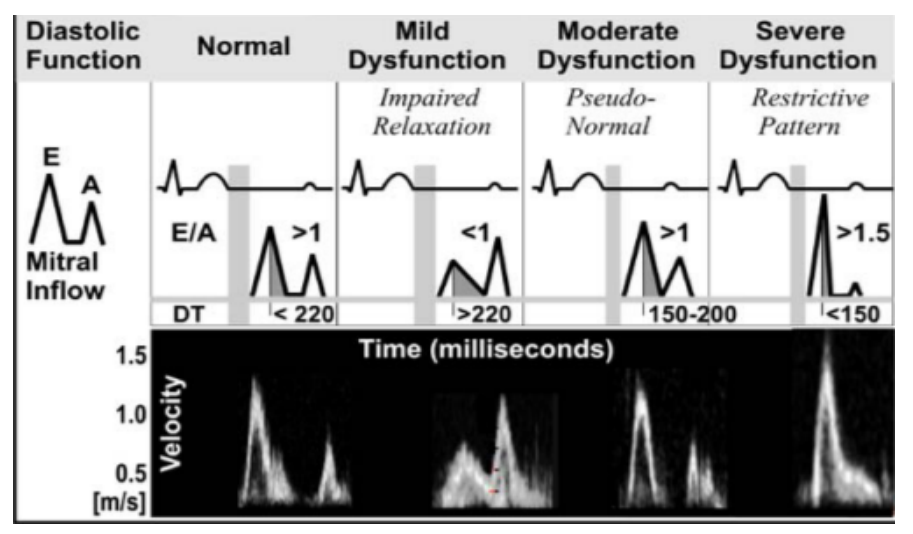

Figure 2. Flow curves in diastolic dysfunctions based on the stages [75] 
M Mode Echocardiography: M Mode imaging method shows cardiac structure as one dimension in the left ventricle and section image is obtained only from the area on which the probe is located. In M Mode imaging, the section cut bey the ultrasound probe should be perpendicular to the posterior wall of the left ventricle. Whereas time is shown on the horizontal axis, depth of the structures is shown on the vertical axis. The longest distance between the septum and posterior wall of the left ventricle gives the diastolic diameter and the shortest distance shows the systolic diameter.

Ejection fraction is calculated by dividing the difference between the square of the diastolic diameter and square of the systolic diameter by square of diastolic diameter [78].

Since this is a one-dimensional imaging, it may give incorrect results in wall motion defects.

Two Dimensional Echocardiography: It is possible to view the heart on different planes with two-dimensional echocardiography which is superior over M Mode echocardiography. Images of the apical chambers are acquired, and ejection fraction, end-systolic and end-diastolic volumes can be calculated by drawing limits of the apical chamber diameters. This method is superior over M Mode echocardiography due to these features [79].

Doppler Echocardiography: Doppler echocardiography is a method in which the rate and direction of bloodstream can be measured. In today's clinical practice; three different methods are used as colour Doppler, pulsed wave Doppler and continuous wave Doppler. This method is often preferred in the measurement of diastolic functions since it is noninvasive [80].

It shows laminar flow, ventricular contraction, turbulence, severity and time of blood pulse as rate-time plot and pressure gradient.

\section{Conclusion}

Acute coronary syndromes are the major thrombotic complications of atherosclerosis and include several clinical pictures occurring due to acute ischemia of cardiac myocardial cells. This clinical picture involves unstable angina pectoris, STEMI, and NSTEMI.

It is critical to establish the correct diagnosis as soon as possible in coronary heart diseases. Triage and appropriate referral of patients with acute myocardial infarction in emergency departments, a rapid diagnosis and treatment interventions will be helpful in reducing mortality and morbidity.

Echocardiography, which is a reliable, easy to use and noninvasive inexpensive method is of paramount importance in establishing the diagnosis rapidly.

\section{References}

1. Kuhn FE, Mohler ER, Satler LF, Reagan K, Lu DY, et al. (1991) Effects of high-density lipoprotein on acetylcholine-induced coronary vasoreactivity. Am J Cardiol 68: 14251430. [Crossref]

2. Julian DG (1996) Acute myocardial infarction: Pre-hospital and in-hospital management-The task force on the management of acute myocardial infarction of the European Society of Cardiology. Eur Heart J 17: 43-63. [Crossref]

3. Onat AS (2006) Analysis of all-cause mortality and coronary events in the Turkish Adult Risk Factor Survey 2005 34: 149-53.

4. Serruys P (1987) Effect of continued rt-PA administration on the residual stenosis after initially successful recanalization in acute myocardial infarction--a quantitative coronary angiography study of a randomized trial. Eur Heart J 8: 1172-1181. [Crossref]
5. DeWood MA, Spores J, Notske R, Mouser LT, Burroughs R, et al. (1980) Prevalence of total coronary occlusion during the early hours of transmural myocardial infarction. $N$ Engl J Med 303: 897-902. [Crossref]

6. Graham I, Atar D, Borch-Johnsen K, Boysen G, Burell G, et al. (2007) European guidelines on cardiovascular disease prevention in clinical practice: executive summary. Eur Heart J 2007. [Crossref]

7. Böger RH, Bode-Böger SM, Thiele W, Junker W, Alexander K, et al. (1997) Biochemical evidence for impaired nitric oxide synthesis in patients with peripheral arterial occlusive disease. Circulation 95: 2068-2074. [Crossref]

8. Reimer K (1979) The" wavefront phenomenon" of myocardial ischemic cell death II. Transmural progression of necrosis within the framework of ischemic bed size (myocardium at risk) and collateral flow. Laboratory Investigation 40: 633-644.

9. Kono T, Morita H, Nishina T, Fujita M, Hirota Y, et al. (1996) Circadian variations of onset of acute myocardial infarction and efficacy of thrombolytic therapy. $\mathrm{J} \mathrm{Am} \mathrm{Coll}$ Cardiol 27: 774-778. [Crossref]

10. Moreno PR, Bernardi VH, López-Cuéllar J, Murcia AM, Palacios IF, et al. (1996) Macrophages, smooth muscle cells, and tissue factor in unstable angina. Implications for cell-mediated thrombogenicity in acute coronary syndromes. Circulation 94: 30903097. [Crossref]

11. Falk E, Fuster V (1995) Angina pectoris and disease progression. Circulation 92: 20332035. [Crossref]

12. Stramba-Badiale M (2006) Cardiovascular diseases in women: a statement from the policy conference of the European Society of Cardiology. Eur Heart J 27: 994-1005. [Crossref]

13. Mosca L (2004) Evidence-based guidelines for cardiovascular disease prevention in women 1. J Am Coll Cardiol 43: 900-921. [Crossref]

14. Myers RH, Kiely DK, Cupples LA, Kannel WB (1990) Parental history is an independent risk factor for coronary artery disease: the Framingham Study. Am Heart $J$ 120: 963-969. [Crossref]

15. Hawe E, Talmud PJ, Miller GJ, Humphries SE; Second Northwick Park Heart Study (2003) Family history is a coronary heart disease risk factor in the Second Northwick Park Heart Study. Ann Hum Genet 67: 97-106. [Crossref]

16. Control CfD (2002) Prevention. Annual smoking-attributable mortality, years of potential life lost, and economic costs--United States, 1995-1999. MMWR Morb Mortal Wkly Rep 51: 300. [Crossref]

17. Critchley JA, Capewell S (2003) Mortality risk reduction associated with smoking cessation in patients with coronary heart disease: a systematic review. JAMA 290: 8697. [Crossref]

18. Barua RS (2003) Reactive oxygen species are involved in smoking-induced dysfunction of nitric oxide biosynthesis and upregulation of endothelial nitric oxide synthase an in vitro demonstration in human coronary artery endothelial cells. Circulation 107: 23422347. [Crossref]

19. Tsuchiya M, Asada A, Kasahara E, Sato EF, Shindo M, et al. (2002) Smoking a single cigarette rapidly reduces combined concentrations of nitrate and nitrite and concentrations of antioxidants in plasma. Circulation 105: 1155-1157. [Crossref]

20. Collins R, Peto R, MacMahon S, Hebert P, Fiebach NH, et al. (1990) Blood pressure, stroke, and coronary heart disease: part 2, short-term reductions in blood pressure: overview of randomised drug trials in their epidemiological context. The Lancet 335 : 827-838. [Crossref]

21. Hebert PR, Moser M, Mayer J, Glynn RJ, Hennekens CH (1993) Recent evidence on drug therapy of mild to moderate hypertension and decreased risk of coronary heart disease. Arch Intern Med 153: 578-581. [Crossref]

22. Eckel RH, Wassef M, Chait A, Sobel B, Barrett E, et al. (2002) Prevention conference VI: Diabetes and cardiovascular disease writing group II: Pathogenesis of atherosclerosis in diabetes. Circulation 105: e138-e43. [Crossref]

23. Kris-Etherton PM (1999) AHA science advisory: monounsaturated fatty acids and risk of cardiovascular disease. J Nutr 129: 2280-2284. [Crossref]

24. Gu K, Cowie CC, Harris MI (1998) Mortality in adults with and without diabetes in a national cohort of the U.S. population, 1971-1993. Diabetes Care 21: 1138-1145. [Crossref]

25. Nguyen XMT, Ho YL, Song RJ, Honerlaw J, Vassey JL, et al. (2016) Relationship Between Serum Cholesterol and Risk of Premature Death From Coronary Heart Disease in Male Veterans: is it Still Continuous and Graded? Circulation 134: A16619-A. 
26. Cannon CP, Braunwald E, McCabe CH, Rader DJ, Rouleau JL, et al. (2004) Intensive versus moderate lipid lowering with statins after acute coronary syndromes. $N$ Engl J Med 351: 714-717. [Crossref]

27. Rexrode KM, Carey VJ, Hennekens CH, Walters EE, Colditz GA, et al. (1998) Abdominal adiposity and coronary heart disease in women. JAMA 280: 1843-1848 [Crossref]

28. Lampert R, Joska T, Burg MM, Batsford WP, McPherson CA, et al. (2002) Emotional and physical precipitants of ventricular arrhythmia. Circulation 106: 1800-1805. [Crossref]

29. Ghiadoni L, Donald AE, Cropley M, Mullen MJ, Oakley G, et al. (2000) Mental stress induces transient endothelial dysfunction in humans. Circulation 102: 2473-2478. [Crossref]

30. Whelton SP, Chin A, Xin X, He J (2002) Effect of aerobic exercise on blood pressure: a meta-analysis of randomized, controlled trials. Ann Intern Med 136: 493-503. [Crossref]

31. Kraus WE, Houmard JA, Duscha BD, Knetzger KJ, Wharton MB, et al. (2002) Effects of the amount and intensity of exercise on plasma lipoproteins. $N$ Engl $J$ Med 347 : 1483-1492. [Crossref]

32. Hulse GK, English DR, Milne E, Holman CD (1999) The quantification of mortality resulting from the regular use of illicit opiates. Addiction 94: 221-229. [Crossref]

33. Alpert JS, Thygesen K, Antman E, Bassand JP (2000) Myocardial infarction redefined-a consensus document of the Joint European Society of Cardiology/American College of Cardiology committee for the redefinition of myocardial infarction: the Joint European Society of Cardiology/American College of Cardiology Committee. J Am Coll Cardiol 36: 959-969. [Crossref]

34. Roffi M (2015) ESC Guidelines for the management of acute coronary syndromes in patients presenting without persistent ST-segment elevation. Eur Heart $J$.

35. Altay H (2012) Editorial: management of acute coronary syndromes in patients presenting without persistent ST-segment elevation: what has changed in the new European Society of Cardiology guideline?

36. (1994) Effects of tissue plasminogen activator and a comparison of early invasive and conservative strategies in unstable angina and non-Q-wave myocardial infarction: results of the TIMI IIIB trial. Circulation 89: 1545-1556. [Crossref]

37. Bhatheja R (2007) Acute coronary syndromes: unstable angina/non-ST elevation myocardial infarction. Critical Cre Clinics 23: 709-735.

38. Bertrand ME, Simoons ML, Fox KA, Wallentin LC, Hamm CW, et al. (2002) Management of acute coronary syndromes in patients presenting without persistent STsegment elevation. Eur Heart J 23: 1809-1840. [Crossref]

39. Van de Werf F, Bax J, Betriu A, Blomstrom-Lundqvist C, Crea F, et al. (2008) Management of acute myocardial infarction in patients presenting with persistent STsegment elevation. Eur Heart J 29: 2909-2945. [Crossref]

40. Falk E (1985) Unstable angina with fatal outcome: dynamic coronary thrombosis leading to infarction and/or sudden death. Autopsy evidence of recurrent mural thrombosis with peripheral embolization culminating in total vascular occlusion. Circulation 71: 699708. [Crossref]

41. Antman E (2001) Acute Myocardial Infarction In: Braunwald E, Zipes D, Libby P, eds. Heart Disease Ed: A textbook of cardiovascular medicine Philadelphia: WB Saunders Company: 1131-1135.

42. Braunwald E (2002) ACC/AHA 2002 guideline update for the management of patients with unstable angina and non "ST-segment elevation myocardial infarction" summary article: a report of the American College of Cardiology/American Heart Association task force on practice guidelines (Committee on the Management of Patients With Unstable Angina). J Am Coll Cardiol 40: 1366-1374.

43. McCarthy BD, Wong JB, Selker HP (1990) Detecting acute cardiac ischemia in the emergency department. J Gen Intern Med 5: 365-373. [Crossref]

44. Sobel BE, Shell WE (1972) Serum enzyme determinations in the diagnosis and assessment of myocardial infarction. Circulation 45: 471-482. [Crossref]

45. Ohman EM, Casey C, Bengtson JR, Pryor D, Tormey W, et al. (1990) Early detection of acute myocardial infarction: additional diagnostic information from serum concentrations of myoglobin in patients without ST elevation. Br Heart J 63: 335-338. [Crossref]

46. Brogan GX Jr, Friedman S, McCuskey C, Cooling DS, Berrutti L, et al. (1994) Evaluation of a new rapid quantitative immunoassay for serum myoglobin versus CK-MB for ruling out acute myocardial infarction in the emergency department. Ann Emerg Med 24: 665-671. [Crossref]
47. Saffe A (2001) Diagnosis of acute myocardial ischemia and infarction in Cardiology, ed. Crawford MH, Dimarco JP, Mosby, London 59: 1161.

48. Kaya UDMG, Okyay UDK, Tulmaç UDM, Cemri M, Yalçın R, Cengel A, et al KORONER STENT UYGULAMASI SONRASINDA TROPONIN T, KREATIN KINAZ VE KREATIN KINAZ-MB ENZIM DÜZEYLERININ MINÖR MIYOKARD HASARINI VE UZUN DÖNEM PROGNOZU GÖSTERMEDEKI YERI.

49. Task Force for Diagnosis and Treatment of Non-ST-Segment Elevation Acute Coronary Syndromes of European Society of Cardiology, Bassand JP, Hamm CW, Ardissino D, Boersma E, et al. (2007) Guidelines for the diagnosis and treatment of non-ST-segment elevation acute coronary syndromes. Eur Heart J 28: 1598-1660. [Crossref]

50. Nakao K, Mukoyama M, Hosoda K, Suga S, Ogawa Y, et al. (1991) Biosynthesis, secretion, and receptor selectivity of human brain natriuretic peptide. Can J Physiol Pharmacol 69: 1500-1506. [Crossref]

51. Brun P, Tribouilloy C, Duval AM, Iserin L, Meguira A, et al. (1992) Left ventricular flow propagation during early filling is related to wall relaxation: a color M-mode Doppler analysis. J Am Coll Cardiol 20: 420-432. [Crossref]

52. Morrow DA, de Lemos JA, Sabatine MS, Murphy SA, Demopoulos LA, et al. (2003) Evaluation of B-type natriuretic peptide for risk assessment in unstable angina/non-STelevation myocardial infarction: B-type natriuretic peptide and prognosis in TACTICSTIMI 18. J Am Coll Cardiol 41: 1264-1272. [Crossref]

53. Antman EM, Cohen M, Bernink PJ, McCabe CH, Horacek T, et al. (2000) The TIMI risk score for unstable angina/non-ST elevation MI: A method for prognostication and therapeutic decision making. JAMA 284: 835-842. [Crossref]

54. Katus HA, Remppis A, Neumann FJ, Scheffold T, Diederich KW, et al. (1991) Diagnostic efficiency of troponin T measurements in acute myocardial infarction. Circulation 83: 902-912. [Crossref]

55. Fox KA, Dabbous OH, Goldberg RJ, Pieper KS, Eagle KA, et al. (2006) Prediction of risk of death and myocardial infarction in the six months after presentation with acute coronary syndrome: prospective multinational observational study (GRACE). BMJ 333: 1091. [Crossref]

56. Anderson JL, Adams CD, Antman EM, Bridges CR, Califf RM, et al. (2007) ACC AHA 2007 guidelines for the management of patients with unstable angina/non STelevation myocardial infarction: a report of the American College of Cardiology/ American Heart Association Task Force on Practice Guidelines (Writing Committee to Revise the 2002 Guidelines for the Management of Patients With Unstable Angina/Non ST-Elevation Myocardial Infarction): developed in collaboration with the American College of Emergency Physicians, the Society for Cardiovascular Angiography and Interventions, and the Society of Thoracic Surgeons: endorsed by the American Association of Cardiovascular and Pulmonary Rehabilitation and the Society for Academic Emergency Medicine. J Am Coll Cardiol 50: e1-e157. [Crossref]

57. Wallentin L (2000) Outcome at 1 year after an invasive compared with a non-invasive strategy in unstable coronary-artery disease: the FRISC II invasive randomised trial. The Lancet 356: 9-16. [Crossref]

58. Fox KA, Poole-Wilson PA, Henderson RA, Clayton TC, Chamberlain DA, et al. (2002) Interventional versus conservative treatment for patients with unstable angina or nonST-elevation myocardial infarction: the British Heart Foundation RITA 3 randomised trial. Randomized Intervention Trial of unstable Angina. Lancet 360: 743-751. [Crossref]

59. Lagerqvist B, Diderholm E, Lindahl B, Husted S, Kontny F, et al. (2005) FRISC score for selection of patients for an early invasive treatment strategy in unstable coronary artery disease. Heart 91: 1047-1052. [Crossref]

60. Killip T 3rd, Kimball JT (1967) Treatment of myocardial infarction in a coronary care unit: a two year experience with 250 patients. Am J Cardiol 20: 457-464. [Crossref]

61. Lee KL, Woodlief LH, Topol EJ, Weaver WD, Betriu A, et al. (1995) Predictors of 30-day mortality in the era of reperfusion for acute myocardial infarction. Results from an international trial of 41,021 patients. GUSTO-I Investigators. Circulation 91: 16591668. [Crossref]

62. Eagle KA, Lim MJ, Dabbous OH, Pieper KS, Goldberg RJ, et al. (2004) A validated prediction model for all forms of acute coronary syndrome: estimating the risk of 6-month postdischarge death in an international registry. JAMA 291: 2727-2733. [Crossref]

63. Timmis A (2000) Acute coronary syndromes: risk stratification. Heart 83: 241-246 [Crossref]

64. Weiss JL, Frederiksen JW, Weisfeldt ML (1976) Hemodynamic determinants of the time-course of fall in canine left ventricular pressure. $J$ Clin Invest 58: 751-760. [Crossref] 
65. Lenihan DJ, Gerson MC, Hoit BD, Walsh RA (1995) Mechanisms, diagnosis, and treatment of diastolic heart failure. Am Heart $J$ 130: 153-166. [Crossref]

66. Oh JK, Appleton CP, Hatle LK, Nishimura RA, Seward JB, et al. (1997) The noninvasive assessment of left ventricular diastolic function with two-dimensional and Doppler echocardiography. J AM Soc Echocardiogr 10: 246-270. [Crossref]

67. Choong CY, Herrmann HC, Weyman AE, Fifer MA (1987). Preload dependence of Doppler-derived indexes of left ventricular diastolic function in humans. $J$ Am Coll Cardiol 10: 800-808. [Crossref]

68. Boersma E, Mercado N, Poldermans D, Gardien M, Vos J, et al. (2003) Acute myocardial infarction. Lancet 361: 847-858. [Crossref]

69. Brutsaert DL, Sys SU, Gillebert TC (1993) Diastolic failure: pathophysiology and therapeutic implications. J Am Coll Cardiol 22: 318-325. [Crossref]

70. DeMaria AN, Blanchard D (1999) 50th anniversary historical article. The hemodynamic basis of diastology. J Am Coll Cardiol 34: 1659-1662. [Crossref]

71. Scalia GM, Greenberg NL, McCarthy PM, Thomas JD, Vandervoort PM (1997) Noninvasive assessment of the ventricular relaxation time constant (L,,) in humans by Doppler echocardiography. Circulation 95: 151-155. [Crossref]

72. Petrie MC, Caruana L, Berry C, McMurray JJ (2002) "Diastolic heart failure" or heart failure caused by subtle left ventricular systolic dysfunction? Heart 87: 29-31. [Crossref]
73. Garcia MJ, Thomas JD, Klein AL (1998) New Doppler echocardiographic applications for the study of diastolic function. $J$ Am Coll Cardiol 32: 865-875. [Crossref]

74. Altuner TK, Bayram NA, Uçar Ö, Canbay A, Sakallı M, Diker E, et al. Primer Hipertansiyonlu Hastalarda Plazma Brain Natriüretik Peptid Düzeyinin Sol Ventrikül Diyastolik Fonksiyonu Ve Sol Ventrikül Kitle İndeksiHo CY, Solomon SD (2006) A clinician's guide to tissue Doppler imaging. Circulation 113: e396-e8. [Crossref]

75. Nishimura RA, Tajik AJ (1997) Evaluation of diastolic filling of left ventricle in health and disease: Doppler echocardiography is the clinician's Rosetta Stone. J Am Coll Cardiol 30: 8-18. [Crossref]

76. Nishimura RA, Abel MD, Hatle LK, Tajik AJ (1990) Relation of pulmonary vein to mitral flow velocities by transesophageal Doppler echocardiography. Effect of different loading conditions. Circulation 81: 1488-1497. [Crossref]

77. Sahn DJ, DeMaria A, Kisslo J, Weyman A (1978) Recommendations regarding quantitation in M-mode echocardiography: results of a survey of echocardiographic measurements. Circulation 58: 1072-1083. [Crossref]

78. Teichholz LE, Kreulen T, Herman MV, Gorlin R (1976) Problems in echocardiographic volume determinations: echocardiographic-angiographic correlations in the presence or absence of asynergy. Am J Cardiol 37: 7-11. [Crossref]

79. Ommen SR, Nishimura RA, Appleton CP, Miller FA, Oh JK, et al. (2000) Clinical utility of Doppler echocardiography and tissue Doppler imaging in the estimation of left ventricular filling pressures: A comparative simultaneous Doppler-catheterization study. Circulation 102: 1788-1794. [Crossref]

Copyright: (C2019 Demirel ME. This is an open-access article distributed under the terms of the Creative Commons Attribution License, which permits unrestricted use, distribution, and reproduction in any medium, provided the original author and source are credited. 